frontal is the great development of the superciliary arches, although slightly less prominent than those of the Neanderthal and Eguisheim. The distance between their outer extremities is no less than $122 \mathrm{~mm}$., while the arches converge at the very root of the nose, leaving a slightly depressed intervening glabellar region, this region differing perceptibly from that of the Neanderthal, in which the glabella is prominent.

Although otherwise well preserved, the under jaw of No. I unfortunately lacks the condyles, which would have enabled us to settle the important question of its relative prognathism. This jaw is very high and massive, and the well-preserved teeth of both present the general characters found amongst the New Caledonians and other modern races of low type. The canines and incisors of the under jaw are worn obliquely and outwardly, those of the upper jaw obliquely and inwardly, although in general to a less extent than amongst the Neolithic races.

The right femur of No. I is not large, but very strong and heavy, and is specially remarkable for its typical forward curvature. The great posterior development of the articular surface of its condyles, taken in connection with the general curvature of the body, shows that the Spy men walked with the knees bent forward, the thigh being obliquely curved forward and downward, and the leg reversed backwards. In other words, the femur was adjusted obliquely to the tibia, which was itself strong, thick and heavy, but very short.

The discoveries at Spy are specially valuable because found associated with other remains which enable us to determine approximately the epoch of analogous finds elsewhere. The already mentioned fauna, as well as the character of the coarse flints occurring in the same undisturbed strata, would seem to indicate that both the Spy men, and their Canstadt and Neanderthal congeners, must have flourished in the époque Moustierienne of French writers, that is, during the early period of the mammoth, and long before the beginning of the Reindeer Age. They were consequently more recent than the race of the epoque Cheliéenne, which was contemporary with Elephas antiques, but of which no actual remains, beyond the objects of its industry, have yet been discovered. That they belonged in any case to pre-Glacial times seems evident from the remarkable absenc of the eindeer, which is not numerously met in West and Central Europe till the Ice period.

M. Fraipont's comparative study of these remains makes it thus abundantly evident that they belong to the Neanderthal type. The two skulls even serve as a sort of missing link between the Neanderthal and the others usually referred to the same race. This race, whose presence in Europe during the early Mammoth Age has now been clearly traced from Stængenæs in Scandinavia to Olmo in Italy, seems in a way to have been resuscitated by the fortunate discovery in the limestone cave on the banks of the Orneau. Their dry bones again assume flesh and blood, and science is enabled confidently to describe the men of Spy as a short, but far from "feeble folk," thick-set, robust, walking knees foremost, and with a figure somewhat analogous to that of the modern Lapps, who also still waddle and are nearly all more or less bandy-legged. Their broad shoulders supported a long, narrow, and depressed head (different therefore from that of the true Papuan, which is long, narrow, and high), with very prominent superciliary arches, enormous orbits; low and retreating brow, high and massive cheek-bones, receding chin. No modern race, however low in the scale of humanity, is collectively characterised by all these traits, so that it may be safely affirmed that the ethnical type of the men of the Mammoth Age has become practically extinct, either through further evolution within itself, or by extirpation, or more probably by fusion with men of a higher physical standard.

It is noteworthy that the points which most separate the men of Spy from the present inhabitants of the globe are precisely those which bring them into closer relation with the anthropoid apes in general, rather than with any particular species of anthropoids. These points, which may thus fairly be described as pithecoid or simian, are chiefly: the prominent superciliary arches, normal in the young male gorilla and adult female orang; the extremely low retreating frontal, constant in the chimpanzee of both sexes and all ages; the almost chinless receding lower jaw, highly typical of gorilla and chimpanzee; lastly, the peculiar curvature of the femur, combined with its adjustment to the tibia, suggesting in the vertical position an attitude somewhat analogous to that of chimpanzee and gorilla. On the other hand, all the other features of cranium, trunk, and limbs are distinctly human, while the cranial capacity alone would suffice to justify the claim of Homo neanderthalensis to membership with the human rather than with the simian family. However great the distance separating him even from the lowest of modern races, far greater, undoubtedly, is the interval between him and the highest of the modern anthropoids. At the same time this interval becomes perceptibly diminished by Gaudry's discovery of Dryopithecus fontanii, an anthropoid ape of the middle Miocene epoch certainly less simian, or rather more human, than any of its present congeners. Its lower jaw is perceptibly less receding than that either of the gorilla, orang, or chimpanzee. The interval tends to be still further reduced when we remember that, although the Homo neanderthalensis is the earliest human type of which any bodily remains have hitherto been discovered, there is a still more primitive race revealed to us by the rude palæolithic implements frequently occurring in association with Elephas antiquus, and in later Tertiary deposits considerably older than the Lower Quaternary of the Spy cave. Whenever any characteristic remains of this primæval race come to light, a distinct approach will have been made towards a solution of the difficult questions connected with the genetic descent of mankind.

A. H. KEANE

\section{AN EXAMINATION OF THE LEAVES OF GYMNEMA SYLVESTRE ${ }^{1}$}

GYMNEMA SYLVESTRE (R. Br.) is an asclepiadaceous plant growing in the Deccan peninsula, from Concan to Travancore ; it is also met with in Assam, and on the Coromandel coast, and is distributed in the continent of Africa. It is a stout woody climber, with long slender branches.

The leaves are opposite, entire, from $\mathrm{I} \frac{1}{2}$ to 3 inches long, and from $I$ to 2 inches broad, elliptic or obovate, acute or cuspidate, rarely cordate at the base, membranous, thinly pubescent on both sides, the upper surface of a darker green than the lower. Gymnema sylvestre is mentioned in the non-official list in the Pharmacopœia of India (1868), and in Dr. Dymock's "Materia Medica of Western India." The powdered root has for a long time been known among the Hindus as a remedy for snake-bites; in such cases it is applied locally to the part affected, and also taken internally in the form of a decoction. But the most curious circumstance connected with this plant was first noticed by Mr. Edgeworth, who discovered that by chewing some of the leaves it destroyed the power of the tongue to appreciate the taste of sugar; he found that powdered sugar, taken immediately after masticating some of the leaves, tasted like so much sand in his mouth, and this effect lasted for twenty-four hours. Dr. Dymock, reviewing this property, said he was unable entirely to confirm this statement; his experience was that sugar taken into the mouth after chewing the fresh plant had a saltish taste, but was still easily recognisable.

I A paper read at a meeting of the Nilgiri Natural History Society Ootacamund, by David Hooper, F.C.S., March $7,{ }^{8} 887$. 
Some authentic leaves were procured by Mr. Lawson from Guindy Park, Madras, who placed them at my disposal for chemical examination. They had a bitterish astringent and slightly acid taste. After chewing one or two leaves it was proved undoubtedly that sugar had no taste immediately afterwards; the saltish taste experienced by others was due to an insufficiency of the leaf being used. Sugar in combination with other compounds in dietetic articles is plainly destroyed as to its taste after using these leaves. In ginger-bread, for instance, the pungency of the ginger is alone detected, the rest is tasteless meal; in a sweet orange the taste of the sugar is so suppressed and that of the citric acid consequently developed that in eating it resembles a lime in sourness. Among the several kinds of foods, drugs, and beverages which affect the palate. Gymnema does not pretend to render them all tasteless; it does not affect pungent and saline things, astringents, and acids. It is limited to apparently two diverse substances, sweets and bitters. It has been noted that sugar taken after the leaf tastes like sand, so I have found that sulphate of quinine taken after a good dose of the leaf tastes like so much chalk. I am not going to propose its use in the administration of nauseous drugs, until the medical properties of the Gymnema have been more studied, otherwise the quantity of the vebicle taken may prove to counteract the effect of the medicines. The experience of several friends as well as my own is that the effect does not last for twenty-four hours as stated, but for only one or two hours ; after that time the tongue resumes its appreciation of all that is sweet or bitter.

The powdered leaves were submitted to the action of various solvents, and by this means it was ascertained that the peculiar property of Gymnema leaves was dissolved out by alcohol, and, as it occurred in the aqueous extract of the residue, it was therefore soluble in water. As benzene and ether took from the leaves certain principles of the same appearance and weight, it was conceived that nothing would be gained by using both solvents; the preliminary extraction was therefore made with ether rectified from water and spirit. The ether extract consisted of chlorophyll and two resins separated by their solubility in alcohol. The resin insoluble in spirit formed the larger portion; it was soluble in chloroform, bisulphide of carbon, and benzene. It was elastic and tenacious, decomposed by warming with nitric acid, the product being precipitated with water; only partially saponified with caustic potash. Sulphuric acid dissolved it in the cold, giving a green solution. It seemed to consist principally of a neutral resin. The resin soluble in spirit was readily saponified with soda, and gave a permanent bluish-green colour with sulphuric acid; like the former resin, it was of an acrid nature, and left a tingling sensation in the throat.

The alcoholic solution of the leaves was almost entirely soluble in water; in fact, by treating the leaves separately by alcohol and water, 36.37 per cent. organic matter was extracted; by treating the drug with water alone 36 per cent. was removed. By direct experiment it was found that in the former extract 0.47 per cent. was an acrid resin similar to those found in the ether extract. The aqueous solution of the substances soluble in alcohol had a decidedly acid reaction; it gave no coloration with ferric chloride, showing absence of tannin. It was deepened in colour with alkalies, but gave a bulky precipitate with sulphuric, nitric, hydrochloric, and acetic acid. It reduced Fehling's solution on boiling, and gave a cloudiness with Nessler, a precipitate with lead acetate, but none with tannin or picric acid. The precipitate caused by sulphuric acid was collected on a filter and washed till it ceased to give a cloudiness with barium chloride. It yielded a greenish powder, insoluble in water, but soluble in alcohol, ether, benzene, and chloroform. With potash, soda, and ammonia it afforded fine red solutions with orange-coloured froth, but they were both precipitated on the addition of the mineral acids. It dissolved in concentrated sulphuric and nitric acids with intense red colour, but in both mixtures it was destroyed and precipitated by water. It fused at about $60^{\circ} \mathrm{C}$. into a blackish brittle mass. Heated in a test-tube it gave off fumes of creosote, but no crystals were obtained in a subliming apparatus. Gently ignited it burned with a bright flame, leaving no ash. It was thrown down as a bulky gray mass by acetate of lead; the lead salt decomposed by sulphuretted hydrogen in water left the substance in the reddish evaporated filtrate from the lead sulphide. The body just described has the characteristics of an organic acid related in some particulars to chrysophanic acid, but having some distinctly peculiar reactions, and possessing the anti-saccharine property ascribed to the leaves. I propose to call it Gymnemic acid.

Gymnemic acid forms more than 6 per cent. of the constituents of Gymnema leaves, in combination with a base which has not been isolated. Another organic acid was present in the lead acetate precipitate, which was identified as tartaric acid, The filtrate from the insoluble lead compounds was treated with sulphuretted hydrogen gas, and the clear liquor after evaporation was examined for sugar. Glucose was detected in some quantity by its immediate and abundant reduction of Fehling's solution ; the sugar examined in a polariscope had a left-handed rotation.

Chloroform agitated with an alkaline solution of the leaf left a crystalline residue of a brownish colour; it had a bitter taste, and acted as a sialagogue. With the ordinary alkaloidal reagents it afforded coloured precipitates, but was a neutral principle. Its further examination together with that of gymnemic acid are reserved for further investigation.

The leaves after being exhausted with ether and then alcohol were treated with water. The gum was detected and estimated in the usual manner. A carbohydrate, optically inactive, and, after boiling with acid, reducing Fehling's solution, was found in this extract.

Diluted soda removed a brownish liquid which consisted of albuminous matters only partially soluble in alcoholic and acetic acid. These were not weighed but calculated by difference.

A solution of I per cent. hydrochloric acid was employed to remove the oxalate of calcium. A microscopical examination of the powdered leaves showed a fair sprinkling of the conglomerate crystals or raphides so well known to exist in rhubarb. The dilution of the acid menstruum rendered this process very tedious, so a stronger acid was used and the marc washed with it until ammonia produced no cloudiness. The collected liquors were allow to deposit, the sediment was then collected on a filter, dried and weighed ; then incinerated and weighed again. The calcium carbonate was calculated into oxalate, and the difference between this and the first weighing was reckoned as pararabin. No oxalic acid was found in a free state.

The ash of Gymnema sylvestre is very high, a fact in accordance with the amount of lime salts it contains. Gentle ignition of the air-dried leaves left as much as $11^{\circ} 65$ per cent., and about one-half of this was calcium carbonate. One hundred parts contained-

I $5^{\circ} 41$ soluble in water.

$78 \%$ I soluble in acid.

5.88 sand and siliceous residue.

The cellulose was estimated by steeping the leaves in sulphuric acid of specific gravity I 50 for 30 hours, washing, drying, burning, and deducting the ash ; this result did not differ materially from the weight of the totally exhausted powder treated with chlorine water. 
The following is a tabulated analysis of the powdered and sun-dried leaves :-

Ether extract (chlorophyll and resins) ...

Alcoholic extract (gymnemic acid, tartaric acid, glucose, neutral bitter principle, resin, \&c.)

Aqueous extract $\dddot{\text { (gum }}$ i $\cdot 4 \overrightarrow{5}$ per cent., glucose, carbohydrate, and extractive) ...

Alkaline extract, by difference (albuminous and colouring matters) $\ldots . .$.

Acid solution $\left\{\begin{array}{lll}\text { calcium oxalate } & \ldots & \ldots\end{array}\right.$

$\begin{array}{lllll}\text { pararabin ... } & \ldots & \ldots & \ldots & 274\end{array}$

$\begin{array}{lllllll}\text { Ash (balance of) } \ldots & \ldots & \ldots & \ldots & \ldots & \ldots & 569\end{array}$

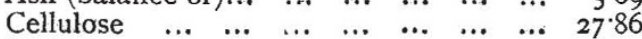

$\begin{array}{lllllllll}\text { Moisture } & \ldots & \ldots & \ldots & \ldots & \ldots & \ldots & \ldots & 6.04\end{array}$

$100 \cdot 00$

\section{NOTES}

THE Conference called by the French Government to consider the means to be adopted for the construction of a photographic chart of the heavens, meets at Paris on Saturday next. We believe that the Astronomer-Royal and Mr. Common have been delegated to represent the Royal and the Astronomical Societies.

The Rev. S. J. Perry and Dr. Copeland have accepted Dr. Bredichin's invitation to observe the total sclar eclipse in August next at his residence near Moscow,

$\mathrm{WE}$ regret to announce the death of Dr. Daniel Rutherford Haldane, who was for some time President of the Royal College of Physicians of Edinburgh. In response to a request by that body he represented the College in the General Council of Medical Education and Registration in the United Kingdom. $\mathrm{He}$ died at his residence in Edinburgh on Tuesday last.

THE annual Conference of the National Union of Elementary Teachers, which has met this week at Portsmouth, has been remarkably successful. It has been attended by about 400 delegates from the different affiliated associations, and by a number of individual members. In his inaugural address, Mr. Girling, the President, made some sensible remarks on technical education in elementary schools. Handicrafts could not be taught in elementary schools, but he was decidedly of opinion that our system of primary education ought to be better adapted to fit children for work when they leave school. He testified to the enterprise and public spirit of the City Guilds, and their Secretary, Sir Philip Magnus, who had started handicraft classes for elementary teachers in London. But he would ask them to co operate in helping to make our educational system a more rational one. Then the teachers would have most valuable aid in preparing the future working-men of the country on intelligent lines, and the technical training of children, now so well begun in our infant-schools through the medium of kindergarten exercises, might be carried still further in the senior schools. At the meeting on Tuesday, a resolution was unanimously passed in favour of the appointment of a Minister of Education. Mr. Salmon, by whom this resolution was proposed, maintained that many educational questions of the highest importance could be adequately settled only by a Minister of much ability and wide experience, invested with large authority and bearing direct and undivided responsibility. Given such a Minister, with great power and noble opportunities, they could justly look to him for great efforts and noble issues.

THE fourth Bulletin of Miscellaneous Information, issued from the Royal Gardens, Kew, contains papers on Manilla hemp, plantain and banana fibre, and pine-apple fibre. Manilla hemp is one of the most important of cordage fibres, and the whole supply comes from the Philippine Islands. Everything made from it can be easily converted into paper of excellent quality. A plant of Manilla hemp may be seen in the Palm House at Kew ; and sets of exhibits in the Kew Museum, No. 2, include the raw fibre, cables, ropes, twine, fine muslin fabrics, "halfstuff," and paper of all kinds, the latter being made from old Manilla ropes. Manilla hemp plants have been introduced from Kew to Jamaica, and to other portions of the West Indies. In favourable situations they grow well, but not so readily as the ordinary bananas and plantains. As the fruit is valueless, they can only be grown for the sake of the fibre, and this alone does not appear to offer sufficient inducement to plant up large areas.

AN Exhibition of the products of the Philippine Archipelago is to be opened at Madrid on June $\mathbf{I}$. It is to be divided into eight sections, with corresponding sections in the Central Commission at Manilla. Amongst these the following are of specially scientific interest :-(I) For the study of the geography, meteorology, terrestrial magnetism, orography, hydrography, anthropology, geology, and mineralogy of the Philippines; (4) the botanical geography of the archipelago, its fauna and flora; (8) general education, public instruction, and the arts and sciences in the Philippines generally. Sub-commissions have been appointed in all the chief places in the archipelago to collect objects for exhibition and information, to be forwarded to the Central Commission, and thence to Madrid.

DURING the next three months a course of lectures on zoology will be delivered at the Zoological Gardens, Regent's Park, by Prof. Beddard. The lecturer will try to make the subject intelligible and attractive to young people, and as the cost will not exceed the bare price of admission to the Gardens, it may be hoped that the course will be largely attended. The arrangements have been made by the Association for the Extension of University Educatiou.

A SMALL Industrial Exhibition was opened on Tuesday last at the Flora Gardens Board School, Hammersmith. Its object is to encourage home industries among the poor.

THE twelfth annual meeting of the members of the Sunday Society was held on Monday, April 4, at the Conduit Street Galleries, Mr. R. Carter in the chair. Mr. Mark H. Judge, Hon. Sec., read the annual report, which claimed for the past year that never before had there been so many or such decisive expressions of public opinion in favour of the Society's object

A REMARKABLE illustration of the puzzling migratory habits of the herring has just been observed on the south west coast of Norway, at the so-called Jæderen, between the towns of Stavanger and Egersund. This district used to be one of the richest herring-fishing grounds in Norway during the spring, but. about twenty-five years ago the fish suddenly and completely disappeared from the coast. Last month enormons shoals once more came under shore, first "striking land" at the same spot as in former times. The quality of the herring is exactly the same as it was twenty-five years ago, and the shoals were accompanied by numerous "herring" whales.

THE first and second parts of a Catalogue of the remains of Siwalik Vertebrata contained in the Geological Department of the Indian Museum, Calcutta, have been sent to us. The work is compiled by Mr. Richard Lydekker, who says that the magnificent Siwalik collection in the Indian Museum is equalled only by that of the British Museum.

AN Exhibition of Seeds will take place at Trondhjem, from July 4 to 10 , in connection with the eighth general Norwegian Agricultural Meeting. At the same time, lectures on the subject will be delivered to the meeting, and a Fisheries Exhibition will also be held. 